

\title{
HYDRONUCLEAR EXPERIMENTS
}

\author{
Robert N. Thorn and Donald R. Westervelt
}

\begin{abstract}
Hyidronuclear experiments, a method for assessing some aspects of nuclear weapon safety, were conducted at Los Alamos during the 1958 - 61 moratorium on nuclear testing. The experiments resulted in subcritical multiplying assemblies or a very slight degree of supercriticality and, in some cases, involved a slight, but insignificant, fission energy release. These experiments helped to identify so-called one-point safety problems associated with some of the nuclear weapons systems of that time. The need for remedial action was demonstrated, although some of the necessary design changes could not be made until after the resumption of weapons testing at the end of 1961 .
\end{abstract}

\section{Introduction}

In his 1976 memoir "A Scientist at the White House," Presidential Science Advisor George Kistiakowsky refers to "single-point safety experiments" performed at Los Alamos in the early 1960s. These safety experiments were laboratory-type high explosive driven criticality experiments carried out to assure the safety of U.S. nuclear weapons in the event of accidental detonation of their high explosive somponents. They are most accurately described as "hydronuclear experiments," and our purpose here is to describe them and the surrounding circumstances in order to make this experience available for future reference.

\section{Background}

U.S. weapon design and testing by 1958 had established two significant new concepts and incorporated them into the weapons stockpile. The first of these was the thermonuclear (TN) weapon (or H-bomb), whose development President Truman had ordered in 1950. Thermonuclear principles were demonstrated in I951 U.S. tests, and the first large TN explosion occurred in 1952. A very high yield fission weapon was tested at that time as a backup, but it had been supplanted by the first deliverable TN weapons by 1954 (the same year in which Soviet Deputy Premier Mikoyan had announced that the Soviet Union had "put the hydrogen bomb in the hands of its troops").

The "fission triggers," or primaries, of the carly TN weapons did not differ significantly fron the pure fission weapons already deployed, and they suffered in this new role from safety and reliability problems. They also were relatively inefficient in their use of fissile material, and the early TN weapons were very large and heavy, severely taxing the bomber aircraft of that time and scarcely suitable for delivery by guided or ballistic missiles.

Many of these problems soon were addressed by the second new concept: the boosted fission primary, which was first tested in 1955. In this design, the 
efficiency of a fission weapon was increased markedly by the incorporation of small amounts of the hydrogen isotopes deutcrium and tritium. Under certain conditions, a thermonuclear reaction between these isotopes produced encrgetic neutrons in large quantities. These neutrons greatly enhanced the fission yield even though the thermonuclear component of the total device yicld was very small. This concept contributed to reliability, efficiency, and significant reduction in sizc and weight as well. The 1955 tests proved the feasibility of this approach to primary design. Developmental weaponization followed quickly in a 1956 test series directed toward the B47 and B52 bombers that were to replace the ponderous, propellor-driven B36, and toward future missile systems.

The United States began a voluntary suspension of nuclear weapons tesis on October 31, 1958. The Soviets joined after two further weapons tests in November. On December 29, 1959 the President, in announcing his decision to continuc the test suspension, made it clear that "during the period of voluntary suspension of nliclear weapons tests the United States will continue its active program of weapon research, development and laboratory-type experiments."

By this time, a trend toward smaller, lower yield, more reliable and safer TN weapons with boosted primaries was well established. The United States also had adopted payload criteria for the relatively small ballistic missiles it would deploy in the 1960s. These criteria were based largely on projections of TN design technology using the new boosted primary concept. In addition, the key nuclear tests that later would be the basis of modern multiple independently targetable recntry vehicle (MIRV) and cruise missile technology had been done. Thus, in several ways, U.S. TN weapon design was well developed when President Eisenhower decided to suspend further testing.

However, unforeseen probiems were soon to arise. The first was a safety problem that will be the focus of the remainder of this report.

\section{One-Point Safety}

Nuclear safety at all times has been a basic military requirement and a fundamental goal of U.S. wcapons designers. The goal always has been to assure that no accident involving a nuclear weapon has a significant chance of resulting in an appreciable nuclear yield. In the case of the carly unboosted fission weapons, nuclear safety was achieved by mechanical means. In most cases, fissile components were separated in part or completely from high explosive components so that an accidental detonation of the latter would not result in assembly of a critical mass of fissile material (that is, a mass whose size and geometry makes it capaulc of sustaining a nuclear chain reaction). In a few cases, other mechanical mcans had 10 be employed. As a result of these measures, none of the few accidents that actually occurred up to that time (nor any since) resulted in any relcase of nuclear energy.

The advent of boosted primaries in $1955-56$ greatly complicated the safety problem, because mechanical solutions werc now much more difficult and in some cases imrossible. They also were somewhat incompatible with the requirement for reduced size and weight. It thus became a major design objective to assure that cven when the fissile and high explosive compenents were fully assembled, there 
would be no nucicar yicld if an accident resulted in detonation of the high explosive. Since such a detonation might start at any single point on or in the explosive components, this design objective came to be known as "onc-point safety."

At that timc, one-point safety behavior of fission wcapons could not reliably be calculated, nor could it be inferred from laboratory experiments that did not involve high explosive compression of fissile material (hydronuclear experiments). Both the available computers and the physical models of that time were inadequate, and the suifty of a particular design could only be cstablished by a nuclear test. If the design in question was safe, the nuclear yicld of such a test would be cssentially zero; but if it was not, the nuclear yicld might be measured in tons of high explosive equivalent. It soon was recognized that the latter result might be avoided in an experiment by a sufficient reduction in the amount of fissile material. In this case, the onc-point safety cxpcriment might be conducted in a reusable containment vessel, and by carly 1958 a design for such a laboratory-type racility was under study.

By the time of the moratorium, one-point safety tests had come to be a significant fraction of all of the nuclear tests involved in development of new boosted designs. For example, of 29 Los Alamos tests of such designs during the 1955, '56, and '57 series, more than one-third were safety tests. In addition, many additional development tests sometimes became necessary because of the results of safety tests. The last nuclear serics before the moratorium was conducted at the Nevada Test Site (NTS) in September and October 1958, following announcement by the President of the October 31 date for the suspension of testing. It was almost entirciy directed toward the onc-point safety objective, and it was only partially successful. Certain designs whose full-yicld performance already had been validated appeared to mect requirements for safety, while others did not. The reasons were discovered only later, well after the suspension of weapons tests had begun and production and deployment of certain designs believed to be safe had proceeded.

\section{Analysis of Past Data}

After U.S. nuclear weapons tests were suspended on October 31,1958 , the designers of boosted fission primaries took advantage of the resulting opportunity to study in more detail the somewhat puzzling results of recent one-point safety tests. For this purpose, they used older, relatively crude methods of calculation as well as more realistic methods and physical models that had only recently begun to be developed. The startling result of this effort first was reported in a June 1959 memorandum by Robert K. Osborne and Arthur R. Sayer, who represented the design group responsible for implosion (fission) weapon design. In this memo, they reported that "... the empirical one-dimensional method ... has yiclded one result which appears to be of such a grave nature that a report on it seems in order." The problem brought to light by analysis of the recent data, supplemented by local, nonnuclear experiments, was that the safety behavior of a given design seemed to depend critically on the particular point at which detonation of the high cxplosive was initiated. This explained some of the unsatisfactory results obtained in the last series of safety tests, and it also cast a serious shadow upon the validity of those that appcared to be satisfactory. The authors conclude: "If it is true that the mode of detonation is very crucial, then several of the . . systems now in stockpile or about to go into stockpile may not be one-point safc." 
Calculations and local hyarodynamic experiments, however, were insufficient to resolve the problem. The safety of four weapon systems that had become operational in 1958 suddenly was in question. The response of the military was immediate. Production was halted in some cases. Weapon handling procedures were severely constrained.

With this new information, only two responsible courses of action were available to the Laboratory: (a) redesign the weapons, and (b) resort to mechanical safing. The iatter was very undesirable, and in some important cases was not feasible. The first appeared to be impossible without further nuclear testing, now ruled out by the moratorium. It was in response to this dilemma that the hydronuclear safety program was devised and carricd out at Los Alamos.

\section{The Hydronuclear Safety Program}

As noted above, it had been recognized well before the suspension of nuclear testing that significant experiments with explosive systems and fissile material could be performed in which tne fission encrgy relcased was small cnough so that containment in fabricated vessels was at least theoretically possible. Such experiments arc described by the term "hydronuclear." They involve a combination of high cxplosive, usually in a nuclear weapon configuration, and fissile material (cnriched uranium and/or plutonium) whose quantity is reduced far below the amount required for a nuclear explosion as the term usually is understood. Such experiments are sometimes referred to as "zcro-yicld tests," although the energy relcased by fissions, while small, is not necessarily zero. (A nuclear explosion has never been defined officially, but we consider a reasonable definition to be a specific fission energy release that is comparable to or greater than that of high explosive itsclf, about one kilocaloric per gram.)

When the moratorium began, there was no discussion of the issue of small, unobservable hydronuclear experiments, and no policy was established in regard to them, but the events described above forced development of such a policy. The gravity of the situstion was explained to government officials in Washington, and on August 26, 1959 Los Alamos proposed a series of experiments on one of the fission primaries whose safety was now in question. The proposal described a series of expcriments that began with a mass of fissile matcrial so small that no nuclear reaction could occur. Successive firings would usc increased amounts of active material in small increments until a subcritical, but multiplying nuclear reaction was detceted. The series would conclude beiow an agreed maximum allowable energy release, and from this it should be possible to assess the specific one-point safety behavior of the stockpiled weapon.

For the other weapons in question, and for other methods of detonation. additional creep-up series of this kind would be required, although it was felt that the number of cxperiments in later scries would be smaller as experience was gained.

Along with this proposal, Los Alamos Dircctor Norris E. Bradbury made the obscrvation that "... (our) peoplc must be confident that what they are being asked to do is honest and consistent with established national policy and that the President knows and understands the full implications of the experiments whether 
announced or not announced." (TWX-DIR-1479) In September 1959 a letter from Atomic Energy Commission (AEC) Chairman John McCone stated that Eisenhower had decided to go ahead with the safety experiments. No immediate announcement was to be made of plans or preparations, but the Kistiakowsky memoir makes it clear that such an announcement was to be in readiness should it become necessary. It was directed that the experiments be done underground at Los Alamos, and preparations to do so began immediately at a remote unused sitc.

On December 18, McCone wrote to Eisenhower stating that Los Alamos would be ready for the first experiment early in January 1960, and he advised Presidential approval of the serics. The letter stated that any nuclear yield would not exceed one pound of high explosive equivalent. Bradbury received a message dated December 31, 1959 stating that the approval of the President had been received and that this type of experiment was "not a nuclear weapon test" under the terms of the moratorium.

The first laboratory hydronuclear experiment was conducted on January 12 , 1960. Eight more were to follow in rapid succession, cach based on the results of the one before, this first series concluding on February 11 . A second serics, involving fewer experiments than the first but with a different point of detonation, ended on March 15. The safety experiments then shifted to another stockpile weapon and the process was repeated. By April 1 the most urgent safety questions had been answered. The largest fission energy release in any experiment thus far, all of which werc conducted at burial depths of 50 to 100 feet, was on the order of onc-thousandth of a pound of high explosive equivalent.

Further direct safeiy experiments would resume some months later, but first an effort was made to use the hydronuclear technique to obtain improved equation of state data for the fissile materials involved. Inadequate data of this kind was one of the reasons for the difficulty in predicting one-point safety behavior. Again, the highest fission energy release was about one-thousandth pound. These experiments were followed by further safety tests on a system soon to enter production, with notably discouraging results. The largest fission yield in this series was about onehundredth of a pound. It was possible from the results obtained to specify a design that would be one-point safe, but the nuclear yield for that design was unknown, in contrast to that of the safer version of the weapon studied in the first hydronuclear series. By good fortune, the safer design for that first system already had been subjected to a full nuclear test well before the moratorium began, and the stockpile weapons could confidently be retrofitted with this version and further production could be altered to the new specifications. No such tested option existed for the weapon not yet in production, and its availability therefore was delayed until well after the resumption of nuclear weapons tests late in 1961.

The value of the retrofit in the first case was demonstrated later at Palomares, Spain, when a B-52 crash resulted in weapons dropped from such height that the high cxplosive in one of them detonated. Plutonium was scattered (a problem that since has becn dealt with by the introduction of insensitive high explosives in many newer weapons), but there was no nuclear yicld. If the weapon had not been modified as a result of the hydronuclear program, the chance of a significant nuclear explosion would have been more than a thousand times greater. 
Hydronuclear safety experiments were done for several other weapon systems, and the most critical safety issues were identificd and in a few cases resolved, although in a other cases it was clear that further nuclear weapons tests would be necessary when the suspension ended. There were 35 hydronuclear experiments in all at Los Alamos, and a smaller number were conducted at the Nevada Test Site by the Livermore Laboratory. In June 1961, near the end of the program, a criticality experiment was performed at Los Alamos on a modified unboosted weapon design. This experiment produced four-tenths of a pound of fission energy, the highest by an order of magnitude of the entire Los Alamos serics. The experiments were terminated when the Sovicts abruptly resumed full-scale nuclear weapons tests on September 1 and President Kennedy directed the AEC and the Laboratories to prepare to do the same.

\section{Lessons Learned}

When the one-point safety problem suddenly arose, the initial response was faltering. Even though the moratorium was less than a year old, much of the Los Alamos testing expertise had dispersed to other activities. A new team was assembled rapidly, however, and the program was supported across the Laboratory much as some of the earlier nuclear test operations had been. One result of this effort was restoration of some of the capability that would be needed for the prompt resumption of underground nuclear testing at the NTS following the surprise abrogation of the moratorium by the Soviets.

As already noted, the hydronuclear program was virtually unnoticed outside of Los Alamos until it was discussed more than a decade later by Kistiakowsky. As in all weapons programs, the details were and remain classified and limited to those with a need to know. The experiments were publicly endorsed, however, by such knowledgeable nuclear testing opponents as Herbert Scoville in a review of the Kistiakowsky memoirs as "not bomb tests because there was no nuclear yicld." We have seen that the yields, while negligibly small, were not zero in all cases, but certainly the experiments could in no way be characterized as nuclear explosions.

This point illustrates an issue that became central during the Carter Administration. A major unresolved question during the trilateral (United States, United Kingdom and Soviet Union) negotiations on a Comprehensive Test Ban (CTB) was that of the scope of the prohibition. Specifically, what kinds of experiments would not be prohibited, and thus would be permitted, under a CTB? The interagency system labored interminably over this question, and a decision finally was reached that small-yield experiments like those in the Los Alamos hydronuclear program would be allowed, that their fission energy release would be limited to 100 pounds (two orders of magnitude larger than any in the hydronuclear program), and that the permitted experiments would be donc underground at the NTS. The last point was arrived at only after extensive consideration of a variety of above-ground containment facilitics like the one referred to earlier in this discussion. The fact is that simple physics mitigated against such containment approaches for hydronuclear cxperiments, and earlicr attempts to use this scheme had resulted in failure. Much of the internal debate during the Carter CTB negotiations was informed and driven by the experience of the Laboratorics during the moratorium, although this experience was unknown to most of the participants in the debate. 
It is clear that high explosive driven criticality experiments (hydronuclear experiments) can address only a limited range of questions. They can contribute essentially nothing to the design of new boosted weapons, nor can they give an adequate assessment of the performance of stockpile primaries when serious questions arise. This is because the conditions for the thermonuclear boosting reaction are established only after considerable fission yield already has becn generated. Their useful role therefore is sharply limited, but it is far from zero under circumstances like those of the moratorium. Even though only a few of the hydronuclear experiments described here even reached criticality, they made it possible to identify, and in some cases to resolve, otherwise crippling safety issues. The hydronuclear experiments served also to maintain some small design and diagnostic capability that was to prove essential when nuclear weapons testing resumed. The ability to conduct such experiments can delay, but not prevent, the eventual disappearance of the nation's nuclear weapen design expertise under a CTB; and in some few cases, it may allow critical stockpile questions to be addressed experimentally.

The most important lesson learned from this experience was that a nation that depends on nuclear weapons for its security can get into serious trouble during a testing moratorium or prohibition. Even with the results that have been described here, it was only by chance that one of the important weapons studied could be retrofitted with a safer design, because the nuclear performance of that design already had been confirmed. The same was not true in another important system because a safe version of that design, even though its specifications now could be defined, had not been, and could not then be, proof tested. When testing resumed, in fact, a long series of nuclear tests was required to arrive at a final design that was both safe and adequate. In addition, tl:e rest resumption led to discovery of a number of unforeseen stockpile reliability problems and allowed them to be resolved by further tests. These problems could not have been identified or solved by hydronuclear experiments alone; thus the experiments described in this report could reduce the risk of a test suspension, but they could not eliminate it. 